\title{
The role of the hospitalist in the continuum of care for patients with hepatic encephalopathy: treatment of inpatient episodes and preventing outpatient recurrence and readmissions
}

\author{
Steven L. Flamm¹, Jasmohan S. Bajaj ${ }^{2}$, Sammy Saab $^{3}$, Robert S. Brown Jr \\ ${ }^{1}$ Division of Medicine and Surgery, Northwestern Medicine Feinberg School of Medicine, Chicago, IL, USA; ${ }^{2}$ Division of Gastroenterology, \\ Hepatology, and Nutrition, Virginia Commonwealth University and McGuire VA Medical Center, Richmond, VA, USA; ${ }^{3}$ Department of Internal \\ Medicine and Surgery, David Geffen School of Medicine at UCLA, Los Angeles, CA, USA; ${ }^{4}$ Weill Cornell Medicine, Center for Liver Disease, New \\ York, NY, USA \\ Contributions: (I) Conception and design: All authors; (II) Administrative support: None; (III) Provision of study materials or patients: None; (IV) \\ Collection and assembly of data: None; (V) Data analysis and interpretation: All authors; (VI) Manuscript writing: All authors; (VII) Final approval of \\ manuscript: All authors. \\ Correspondence to: Steven L. Flamm, MD. Professor of Medicine and Surgery, Northwestern Medicine Feinberg School of Medicine, Chicago, IL, \\ USA. Email: s-flamm@northwestern.edu.
}

\begin{abstract}
Hepatic encephalopathy (HE) is a common complication of advanced cirrhosis that is seen in the majority of patients at some point. Manifesting as a wide spectrum of neuropsychiatric abnormalities, HE has many consequences; increased morbidity and mortality, bothersome symptoms affecting quality of life and routine activities (e.g., working, driving), substantial caregiver burden, frequent hospital admissions and readmissions and associated economic strains. The manifestations of $\mathrm{HE}$ are potentially reversible with medical treatment, frequently in the inpatient setting, and preventable with outpatient maintenance of remission. However, breakdowns across the continuum of care for $\mathrm{HE}$ patients are responsible for frequent hospital readmissions; hospitalists, who play a pivotal role in improving the management of HE, can improve these outcomes. The authors are US hepatologists with expertise and experience in managing HE and members of the Chronic Liver Disease Foundation (CLDF), a nonprofit 501(c)(3) educational organization dedicated to raising awareness of liver disease. The goals of this article are to provide a thorough review of $\mathrm{HE}$; to describe how $\mathrm{HE}$ is currently managed and identify ways to improve diagnosis and treatment; to review the role of the hospitalist in managing and preventing $\mathrm{HE}$ episodes; and to provide strategies to reduce hospital readmissions and improve outcomes.
\end{abstract}

Keywords: Hepatic encephalopathy (HE); treatment; recurrence; readmissions; prevention

Received: 04 February 2020; Accepted: 02 September 2020; Published: 25 December 2020.

doi: $10.21037 /$ jhmhp-20-23

View this article at: http://dx.doi.org/10.21037/jhmhp-20-23

\section{Introduction}

Cirrhosis is characterized by inflammation leading to scarring (i.e., fibrosis) with the formation of regenerative nodules in the liver that cause architectural distortion. In early or compensated cirrhosis, patients are largely asymptomatic and have a favorable prognosis. As structural changes and increased intrahepatic vasoconstriction progress, patients develop overt complications of cirrhosis, referred to as decompensated cirrhosis. Hepatic dysfunction, portal hypertension, and the formation of collateral vessels (portosystemic shunts) ensue, and the disease becomes more complex. Hepatic encephalopathy (HE) is a common complication of advanced cirrhosis that manifests as a wide spectrum of potentially reversible neuropsychiatric abnormalities, which includes a subclinical covert (CHE) and clinically apparent overt HE (OHE) dimension (1). As 
most cases of $\mathrm{HE}$ within the hospital are OHE, OHE will be discussed throughout the rest of this paper and referred to as HE.

In the US, the estimated prevalence of cirrhosis is approximately 5.5 million cases (2). It is estimated that $30-50 \%$ of cirrhotic patients experience $\mathrm{HE}$, but given the difficulties in diagnosis, the true prevalence of $\mathrm{HE}$ is likely substantially higher. Studies suggest that the majority of cirrhotic patients will experience $\mathrm{HE}$ at some point during their illness $(3,4)$. The CDC ranked cirrhosis as the 11th leading cause of death in the US in 2017 (5).

Data suggest that HE results in the utilization of more healthcare resources in adults than any other manifestation of liver disease (6). As a result of the severity of $\mathrm{HE}$ and the increased risk of mortality (7), emergency room visits and hospital admissions are common and, as such, hospitalists are integral to HE management. However, hospital readmissions are frequent and are often a direct result of disease mismanagement or interruption of continuity of care. With the ability to manage varying aspects of patient care, hospitalists can help resolve the disconnect that exists as an HE patient moves across the continuum of care (8) and play a pivotal role in providing appropriate management of $\mathrm{HE}$ in order to improve outcomes.

The authors of this article are US hepatologists with expertise and experience in managing $\mathrm{HE}$ and members of the Chronic Liver Disease Foundation (CLDF), a nonprofit 501(c)(3) educational organization dedicated to raising awareness of liver disease. The goals of this article are to provide a thorough review of HE; describe ways to improve diagnosis and treatment; review the role of hospitalists in managing and preventing HE episodes; and ultimately provide strategies for how hospitalists can contribute to achieving the ultimate goal, which is to reduce hospital readmissions and improve outcomes.

\section{Defining HE}

\section{Pathophysiology}

The pathophysiology of HE is complex (9). Multiple factors are believed to functionally impair neuronal cells, with ammonia (NH3) considered the primary factor. Urea from dietary proteins are metabolized to $\mathrm{NH} 3$ by gut bacteria; $\mathrm{NH} 3$ is then metabolized by the liver and cleared by the kidneys. In cirrhosis, hepatic dysfunction impairs the metabolism of $\mathrm{NH} 3$ and portal hypertension shunts blood through portosystemic collaterals, concentrated with $\mathrm{NH} 3$, to the brain (10). After crossing the blood-brain-barrier, NH3 initiates pathophysiologic processes responsible for neuronal impairment and ultimately leads to the neurologic manifestations associated with HE. However, multiple recent and prior investigations have determined that serum $\mathrm{NH} 3$ levels are not necessarily reflective of the sum total of these pathophysiological changes $(11,12)$ and $\mathrm{NH} 3$ activity is not reflected by serum $\mathrm{NH} 3$ levels.

\section{Classification and clinical presentation}

Grading HE is an important part of the clinical assessment. Originally, the West Haven criteria categorized HE from grade I to grade IV based on various clinical parameters $(13,14)$, but these criteria were considered too subjective. In recent years, the International Society for Hepatic Encephalopathy and Nitrogen Metabolism (ISHEN) reached a consensus regarding classification and nomenclature of HE. The ISHEN criteria describe HE as covert (CHE), which is detected using specialized testing, and overt (OHE), which is detected by clinical symptoms. The American Association for the Study of Liver Diseases (AASLD) guidelines refer to both classification systems (1) Table 1 describes these criteria and the HE symptoms characteristic of each stage. OHE is responsible for hospitalizations, and is the condition that hospitalists can intervene on and improve outcomes.

\section{The burdens of HE}

\section{HE negatively impacts patients' lives}

There are multiple negative impacts of $\mathrm{HE}$ on healthrelated quality of life. Patients may suffer from sleep disturbances, which manifest as sleep-wake inversion (restless nights and excessive daytime sleepiness) (15). They can lose the ability to work and/or manage the household and may refrain from recreational activities (16). HE can interfere with patients' social lives with feelings of disease stigmatization leading to social isolation (17). Defects in visuospatial assessment, attention, memory, response speed, information processing, and increased fatigue are all symptoms that affect driving ability (18). As HE progresses, high levels of supportive care needs result in increased dependency on others (6). Caregivers are also adversely affected as hospital readmissions increase and independence decreases (19-21).

The manifestations described above contribute to impaired 
Table 1 Hepatic encephalopathy classifications, according to ISHEN and West Haven Criteria, and associated symptoms $(1,9,13,14)$

\begin{tabular}{lll}
\hline ISHEN & West Haven Criteria & \multicolumn{1}{c}{ Symptoms } \\
\hline Covert & Minimal & $\begin{array}{l}\text { No clinical evidence of mental change, but with psychometric or neuropsychological alterations of } \\
\text { tests exploring psychomotor speed/executive functions or neurophysiological alterations }\end{array}$ \\
& Grade I & $\begin{array}{l}\text { Trivial lack of awareness; euphoria or anxiety; shortened attention span; impairment of addition or } \\
\text { subtraction; altered sleep rhythm }\end{array}$ \\
Grade II & $\begin{array}{l}\text { Lethargy or apathy; disorientation of time; obvious personality change; inappropriate behavior; } \\
\text { dyspraxia*; asterixis (i.e., flapping tremor) }\end{array}$ \\
& Grade III & Somnolence to semi-stupor responsive to stimuli; confused*; gross disorientation; bizarre behavior \\
& Grade IV & Coma*
\end{tabular}

${ }^{*}$ Most common symptoms upon presentation of HE. Adapted from references $(1,9,13,14)$. ISHEN, International Society for Hepatic Encephalopathy and Nitrogen Metabolism.

quality of life (22). This has been well established in many studies; quality-of-life scoring systems show that most physical, mental, and social domains are severely compromised in HE patients (16).

\section{Frequent hospitalizations, recurrence, and readmissions}

HE is primarily managed in the hospital setting (23) and is the most common cause of patients' initial liver disease-related hospitalizations (24). HE is responsible for 100,000-150,000 annual US hospital admissions (25). The development of HE during hospitalization is also common; up to $80 \%$ of $\mathrm{HE}$ episodes are precipitated by an event such as infection or gastrointestinal bleeding (26). Even in its mildest form, $\mathrm{HE}$ is a risk factor for future, more severe episodes (1); one study estimated that risk of recurrence increased by $23 \%$ with every unit increase in the number of prior overt HE episodes (27). Most patients require maintenance medications at discharge to protect against $\mathrm{HE}$ recurrence, but data indicate that this need is not being met, resulting in a revolving door of $\mathrm{HE}$ episodes and readmissions. Table 2 shows that HE readmissions are frequent, and HE is often the most common reason for readmission in patients hospitalized with decompensated cirrhosis $(16,19,28-32)$.

Rehospitalization for HE can lead to severe consequences in an already seriously ill patient. In one study, patients with more frequent readmissions had a significantly higher risk of subsequent mortality (hazard ratio 1.08 per unit increase in hospitalization rate, $\mathrm{P}<0.001$ ).

Repeated episodes may cause irreversible neurologic damage. Bajaj and colleagues showed that defects associated with HE (e.g., deficits in memory, response inhibition, and learning) were persistent and cumulative after subsequent episodes (20). Additionally, patients' quality of life may be affected by the fear of recurrence (33).

\section{Economic burdens}

The economic burden of HE is substantial. Medication costs, morbidity and mortality, quality of life, and outpatient care contribute to this economic strain (34), but hospitalization costs are the largest contributor to overall HE-related costs (35). HE-related hospitalization costs have continued to rise, with one analysis estimating that these costs escalated from $\$ 4.68$ billion in 2005 to $\$ 7.25$ billion in 2009. Also, the proportion of patients with major and extreme severity of illness significantly increased $(\mathrm{P}<0.0001)$, as did the average length of inpatient stay (from 8.1 to 8.5 days; $\mathrm{P}=0.019$ ) (25). As expected, frequent readmissions contribute to cost. In an analysis of hospital readmission costs in cirrhotic patients, per-patient costs were $\$ 73,252$ for those readmitted within 30 days, $\$ 62,053$ for those readmitted after 30 days, and $\$ 5,719$ (outpatient costs) for those not readmitted (30).

\section{Inpatient assessments and treatment}

\section{A diagnosis of exclusion}

The diagnosis of HE is primarily based on the exclusion of other causes of brain dysfunction $(1,9)$. As shown in Figure 1, when a patient presents with symptoms and physical findings consistent with $\mathrm{HE}$, recognizing and excluding other common disorders and identifying precipitating 
Table 2 Data on HE recurrence, hospital admissions, and readmissions

\begin{tabular}{|c|c|c|}
\hline Study & Patients and methods & Results \\
\hline Kim et al. (27) & $\begin{array}{l}\text { Nationwide Inpatient Sample data analysis. } \\
65,072 \text { discharge records associated with } \\
\text { hospitalization for complications of cirrhosis }\end{array}$ & $\begin{array}{l}41 \% \text { of hospitalizations among patients with cirrhosis were } \\
\text { attributed to } \mathrm{HE} \text {; HE associated with a two-fold higher probability } \\
\text { of in-patient mortality }(\mathrm{P}<0.01)\end{array}$ \\
\hline Neff et al. (29) & $\begin{array}{l}\text { Premier Research Database (information } \\
\text { from >500 US hospitals). } 8,766 \text { patients } \\
\text { discharged from June } 2010 \text { to December } \\
2011 \text { with primary diagnoses of HE }\end{array}$ & $\begin{array}{l}\text { Incidence rates for all-cause readmissions were } 27.4 \% \text { ( } 30 \text { days) } \\
\text { and } 56.4 \% \text { (one year); rates for HE-related readmissions were } \\
17.6 \% \text { ( } 30 \text { days) and } 39.5 \% \text { ( } 1 \text { year) }\end{array}$ \\
\hline $\begin{array}{l}\text { Chirapongsathorn } \\
\text { et al. (30) }\end{array}$ & $\begin{array}{l}2,075 \text { patients with index cirrhosis-related } \\
\text { hospital admissions }\end{array}$ & $\begin{array}{l}655 \text { patients readmitted within } 30 \text { days of hospitalization ( } 32 \% \\
\text { readmission rate); HE-related readmissions within } 30 \text { days of } \\
\text { hospitalization accounted for } 13.6 \% \text { of all readmissions }\end{array}$ \\
\hline Masadeh et al. (31) & $\begin{array}{l}\text { One-year retrospective chart review. } 139 \\
\text { patients admitted with a complication related } \\
\text { to liver cirrhosis ( } 36 \% \text { with } \mathrm{HE})\end{array}$ & $\begin{array}{l}31 \% \text { of patients overall were readmitted within } 30 \text { days; } 47 \% \text { of } \\
\text { these cases were attributed to HE; HE was the most common } \\
\text { cause of readmission within } 30 \text { days, followed by fluid overload }\end{array}$ \\
\hline
\end{tabular}

Adapted from references $(19,20,27-32)$.

factors that alter the level of consciousness is the first step $(1,9)$. It is also important to recognize that multiple precipitating events may frequently coexist (36). Finally, patients with noncirrhotic portal hypertension are also at risk for HE (37).

Clinical evaluation, laboratory tests, and cerebral imaging are recommended in a patient with suspected $\mathrm{HE}$ (Figure 1) (9). Clinical evaluation involves obtaining a detailed history about symptoms and medications (including those for pre-existing HE, over-the-counter and illicit substances), and performing a physical examination (neurologic, psychiatric, and assessment of exacerbating factors) (9). There is no specific biochemical diagnostic test for HE, but a complete laboratory evaluation can help to exclude other factors and/or causes. Serum NH3 levels are rarely useful, as the levels do not correlate with symptoms and do not change practice $(1,38)$. While the positive predictive value is poor, a low serum NH3 in a confused patient likely indicates the absence of HE (1). The combined increased risk of falls in HE and increased risk of bleeding with chronic liver disease (as a result of coagulopathy and thrombocytopenia) put patients at risk for subarachnoid, intracranial hemorrhage or a cerebral vascular event and warrants cerebral imaging in patients with no prior history of $\mathrm{HE}(9)$.

\section{Inpatient treatment}

Identification and correction of precipitating factors The treatment of HE begins with the aim of improving 


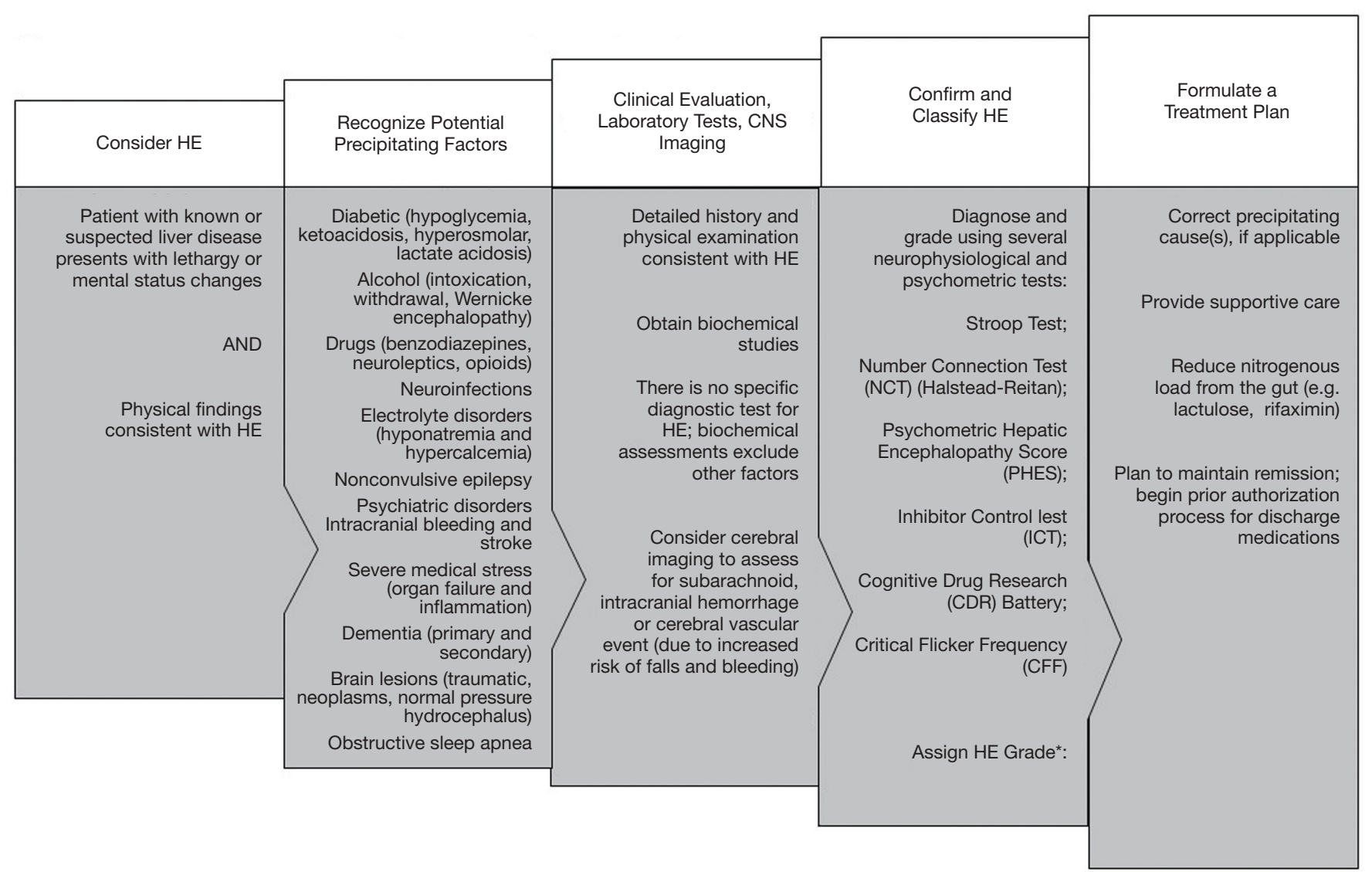

Figure 1 Diagnosis and treatment of hepatic encephalopathy in the hospitalized patient. *See Table 1 for more details. Adapted from references $(1,9)$. HE, hepatic encephalopathy; CNS, central nervous system.

mental status and requires active therapy (1). Treatment of episodic HE can be divided into inpatient induction/ immediate treatment and outpatient maintenance of remission (21). Figure 1 provides a suggested treatment plan for the hospitalized HE patient. Rapid identification and correction of the precipitant(s) is considered firstline management (39). Efforts should be made to treat infections, control gastrointestinal bleeding, and correct dehydration and electrolyte imbalances, for example $(1,36)$.

\section{Treating HE}

Pharmacologic treatment of HE relies on therapies that reduce the nitrogenous load from the gut. Lactulose is first-line therapy. It is a non-absorbable disaccharide that is fermented in the colon and metabolized by microbiota to produce lactic acid, thereby lowering colonic $\mathrm{pH}$. The cathartic effect of lactulose can increase fecal nitrogen excretion with up to a four-fold increase in stool volume (40); this therapeutic effect also commonly causes abdominal distension, cramping, diarrhea, electrolyte changes, and flatulence (1). Lactulose is administered orally, through a nasogastric tube or via retention enemas (1). For oral and nasogastric tube administration, 30 to $45 \mathrm{~mL}(20-30 \mathrm{~g})$ is initially administered three to four times daily, with dose titration to produce two to three soft stools per day; for enemas, $300 \mathrm{~mL}$ is administered in $1 \mathrm{~L}$ of water (9).

The addition of rifaximin to lactulose is recommended, as this combination has demonstrated faster reversal of $\mathrm{HE}$ and shorter hospital stays $(1,9)$. Rifaximin is a minimally absorbed, oral antibiotic that decreases $\mathrm{NH} 3$-producing gut bacteria, thereby lowering serum NH3 (9). Rifaximin is taken orally twice a day, with or without food, and does not require dose adjustments in hepatic or renal insufficiency. Older antibiotics that were previously used for HE include neomycin and metronidazole. Although these drugs still have their advocates (1), significant side effects (e.g., nephrotoxicity and ototoxicity with neomycin; neuropathy with metronidazole) limit their use $(1,9)$. 
Table 3 The efficacy of lactulose and/or rifaximin for HE remission

\begin{tabular}{|c|c|c|}
\hline $\begin{array}{l}\text { Maintenance } \\
\text { medication(s) }\end{array}$ & Patients and methods & Results \\
\hline Lactulose (41) & $\begin{array}{l}\text { Open-label study; } 140 \text { patients randomized to } \\
\text { daily placebo or lactulose after recovery from } \\
\text { an episode of OHE; patient follow-up over a } \\
\text { median of } 14 \text { months }\end{array}$ & $\begin{array}{l}19.7 \% \text { of lactulose-treated patients ( } 12 \text { of } 61) \text { experienced recurrent } \\
\text { OHE vs. } 46.9 \% \text { ( } 30 \text { of } 64) \text { in the placebo arm }(P=0.001)\end{array}$ \\
\hline $\begin{array}{l}\text { Rifaximin and } \\
\text { Lactulose (39) }\end{array}$ & $\begin{array}{l}\text { Rifaximin ( } n=140 \text { ) vs. placebo }(n=159) \text { for the } \\
\text { secondary prevention of episodic OHE in adult } \\
\text { patients with } 2 \text { or more previous episodes } \\
\text { of unprecipitated HE (now in remission); the } \\
\text { majority of patients ( }>90 \% \text { ) were taking lactulose }\end{array}$ & $\begin{array}{l}\text { Breakthrough HE lower in the rifaximin group ( } 31 \text { of } 140) \text { vs. } \\
\text { placebo group ( } 73 \text { of } 159) \text {; hazard ratio of } 0.42 \text { ( } 95 \% \mathrm{Cl}, 0.28-0.64 \text {; } \\
\mathrm{P}<0.001) ; 50 \% \text { reduction in hospitalizations for the rifaximin group } \\
\text { (19 of } 140) \text { vs. the placebo group ( } 36 \text { of } 159) \text {; similar AEs amongst } \\
\text { the two groups }\end{array}$ \\
\hline $\begin{array}{l}\text { Rifaximin vs. } \\
\text { Lactulose (44) }\end{array}$ & $\begin{array}{l}\text { Retrospective chart review of } 145 \text { patients who } \\
\text { received lactulose ( } 30 \mathrm{cc} \text { BID) for } \geq 6 \text { months } \\
\text { and then rifaximin ( } 400 \mathrm{mg} \text { TID) for } \geq 6 \text { months }\end{array}$ & $\begin{array}{l}\text { Fewer hospitalizations }(0.5 \text { versus } 1.6 ; \mathrm{P}<0.001) \text {, fewer days } \\
\text { hospitalized }(2.5 \text { versus } 7.3 ; \mathrm{P}<0.001) \text {, fewer total weeks } \\
\text { hospitalized ( } 0.4 \text { versus } 1.8 ; \mathrm{P}<0.001) \text {, and lower hospitalization } \\
\text { charges per patient }(\$ 14,222 \text { versus } \$ 56,635) \text { were reported } \\
\text { during the rifaximin period; more patients had asterixis, diarrhea, } \\
\text { flatulence, and abdominal pain during the lactulose period }(\mathrm{P}<0.001)\end{array}$ \\
\hline
\end{tabular}

Adapted from references (39,41-44). ITT, intent to treat; BID, twice daily; TID, three times daily.

\section{Assembling a maintenance plan: prevention of recurrence with chronic therapy}

The latter half of the HE treatment plan involves outpatient maintenance of remission to prevent recurrence and future hospitalizations. This plan needs to be formulated during inpatient treatment in conjunction with the outpatient care team as some discharge medications for HE commonly require prior authorizations. Prior authorization for maintenance medications is recommended during inpatient treatment so that the prescription can be readily available upon discharge.

The choice of maintenance medication(s) is the same as those used for therapy of active disease. Although there are no randomized, placebo-controlled trials supporting the use of lactulose for maintenance of remission from HE, open-label data and clinical experience support its use (1). Lactulose continues to require titration to achieve two to three soft stools per day while avoiding diarrhea and its consequences (e.g., dehydration, electrolyte abnormalities); patient dissatisfaction regarding these side effects often limit long-term use (9). In fact, readmission persists despite lactulose use, which is possibly related to how unpalatable it is. According to AASLD guidelines, rifaximin added to lactulose is the best-documented regimen to maintain remission in patients who have already experienced one or more bouts of $\mathrm{HE}$ while on lactulose treatment after their initial episode of HE $(1,39)$ In some cases, rifaximin monotherapy is the best option, especially in patients who poorly tolerate lactulose (9). Table 3 summarizes data on the use of lactulose and/or rifaximin for maintenance of remission in HE (39,41-44).

\section{Transitioning to the outpatient setting and outpatient management}

The period after discharge for cirrhotic patients is often described as "a high risk one"; patients may be on new medications, and their care is being transitioned from inpatient to outpatient (19). Hospitalists play a critical role in ensuring that HE treatment goals are optimized. This includes stressing the need for compliance with maintenance HE medications, setting close interval followup appointments with outpatient providers, and involving family and/or caregivers in understanding the importance 
of chronic medications and outpatient care. Careful counseling of family members and caregivers is critical to ensure adherence to medications, follow-up visits, and to alert the discharging facility in the case of deterioration. Unfortunately, hospitalists are often challenged with several obstacles when attempting to meet these goals.

Data suggest that most patients hospitalized for $\mathrm{HE}$ do not receive maintenance medications upon discharge. One study found, after reviewing insurance claim data for prescriptions filled in $2009(\mathrm{n}=13,623), 2010(\mathrm{n}=15,529)$, and $2011(\mathrm{n}=16,328)$ that $89.2 \%, 87.8 \%$, and $86.4 \%$ of patients with $\mathrm{HE}$ had inpatient claims for $\mathrm{HE}$, respectively, and $60.3 \%, 62.3 \%$, and $63.9 \%$ did not receive ongoing treatment (29). Hospitalists oversee the maintenance plan, including prescribing the correct medications and helping the patient to have access to them following discharge. Patients should be made aware that if they cannot obtain the medications for insurance-related reasons, the outpatient provider should be contacted as they can often help obtain coverage. Patients and caregivers should be taught how to recognize the symptoms of $\mathrm{HE}$ and to appreciate the importance of long-term therapy.

Discharging a patient with $\mathrm{HE}$ also involves addressing the ability to drive, as this is an important issue. Although fitness to drive is known to be compromised in patients with $\mathrm{HE}$, there are no definitive guidelines or laws for practitioners to refer to when advising patients about driving. Yet, driving in the setting of recent $\mathrm{HE}$ is not advised. It is also important to be mindful of individual state requirements, as certain states require that healthcare professionals refer potentially unsafe drivers to motor vehicle authorities (9).

Patient adherence remains a factor in the recurrence of HE; lactulose non adherence is the leading cause for hospital readmission or recurrence of HE (9). A retrospective chart review (Table 2) found that HE recurrence and hospital readmission were often associated with failure to appropriately titrate lactulose-specifically, inadequate number of bowel movements and lack of awareness of dose titrations. Also, there was a failure to communicate worsening symptoms to providers (29). There are also compliance issues with rifaximin. A common misconception is that long-term use of an antibiotic is unnecessary and that its use is associated with bacterial resistance. As rifaximin is only minimally absorbed, resistance has not been an issue and rates of Clostridium difficile infections are low. Hospitalists need to counsel patients on these facts, specifically that although rifaximin is an antibiotic, it needs to be taken long-term and noncompliance will greatly increase chances of readmission.

\section{Conclusions}

$\mathrm{HE}$ is a burdensome complication of cirrhosis that is characterized by episodic occurrences that frequently require hospitalization. The consequences of $\mathrm{HE}$ affect patients physically (symptoms that range from confusion and tremors to coma) and emotionally (decreased quality of life). Optimizing the continuum of care is critical to prevent HE recurrence and re-hospitalization, which involves monitoring precipitating factors, and ensuring that patients are compliant with appropriate maintenance medications. Lack of appropriate post-discharge care results in frequent HE-related hospital readmissions. Hospitalists play a central role in minimizing recurrence and hospital readmission by initiating a care plan with lactulose and rifaximin and counseling patients on the importance of chronic treatment.

\section{Acknowledgments}

Rachel E. Bejarano, PharmD and Lisa Pedicone, $\mathrm{PhD}$ provided medical writing assistance.

Funding: Supported by an educational grant from Salix Pharmaceuticals.

\section{Footnote}

Conflicts of Interest: All authors have completed the ICMJE uniform disclosure form (available at http://dx.doi. org/10.21037/jhmhp-20-23). SLF reports personal fees from Salix Speaker Consultant, outside the submitted work. JSB reports grants from Valeant, personal fees from Norgine, grants from Grifols, grants from Kaleido, grants from Mallinckrodt, during the conduct of the study. SS reports personal fees from Salix, during the conduct of the study. RSB reports grants and personal fees from Intercept, grants and personal fees from Dova, grants and personal fees from Shionogi, grants and personal fees from Salix, outside the submitted work.

Ethical Statement: The authors are accountable for all aspects of the work in ensuring that questions related to the accuracy or integrity of any part of the work are appropriately investigated and resolved.

Open Access Statement: This is an Open Access article 
distributed in accordance with the Creative Commons Attribution-NonCommercial-NoDerivs 4.0 International License (CC BY-NC-ND 4.0), which permits the noncommercial replication and distribution of the article with the strict proviso that no changes or edits are made and the original work is properly cited (including links to both the formal publication through the relevant DOI and the license). See: https://creativecommons.org/licenses/by-nc-nd/4.0/.

\section{References}

1. Vilstrup H, Amodio P, Bajaj J, et al. Hepatic encephalopathy in chronic liver disease: 2014 Practice Guideline by the American Association for the Study of Liver Diseases and the European Association for the Study of the Liver. Hepatology 2014;60:715-35.

2. The Burden of Gastrointestinal Diseases. Bethesda, Maryland. American Gastroenterological Association; 2001:41-2.

3. Amodio, P, Del Piccolo, F, Petteno E, et al. Prevalence and prognostic value of quantified electroencephalogram (EEG) alterations in cirrhotic patients. J Hepatol 2001;35:37-45.

4. Romero-Gómez M, Boza F, Garcia-Valdecasas MS, et al. Subclinical hepatic encephalopathy predicts the development of overt hepatic encephalopathy. Am J Gastroenterol 2001;96:2718-23.

5. National Vital Statistics Report. Deaths: Final Data for 2017. Available online: https://www.cdc.gov/nchs/data/ nvsr/nvsr68/nvsr68_09-508.pdf. Accessed July 17, 2019.

6. Rakoski MO, McCammon RJ, Piette JD, et al. Burden of cirrhosis on older Americans and their families: analysis of the health and retirement study. Hepatology 2012;55:184-91.

7. Cordoba J, Ventura-Cots M, Simon-Talero M, et al. Characteristics, risk factors, and mortality of cirrhotic patients hospitalized for hepatic encephalopathy with and without acute-on-chronic liver failure (ACLF). J Hepatol 2014;60:275-81.

8. The Future Role of Hospitalists; The Hospitalist 2005. Available online: https://www.the-hospitalist. org/hospitalist/article/122918/future-role-hospitalists. Accessed July 17, 2019.

9. Reau N, Brown RS, Flamm SL, et al. Step-by-Step Approach to the Diagnosis and Management of Hepatic Encephalopathy in the United States. Gastro and Hep 2016;12:S5.

10. Tapper EB, Jiang ZG, Patwardhan VR. Refining the ammonia hypothesis: a physiology-driven approach to the treatment of hepatic encephalopathy. Mayo Clin Proc 2015;90:646-58.

11. Bajaj JS, Bloom PP, Chung RT, et al. Variability and Lability of Ammonia Levels in Healthy Volunteers and Patients With Cirrhosis: Implications for Trial Design and Clinical Practice. Am J Gastroenterol 2020;115:783-5.

12. Haj M, Rockey DC. Ammonia Levels Do Not Guide Clinical Management of Patients With Hepatic Encephalopathy Caused by Cirrhosis. Am J Gastroenterol 2020;115:723-8.

13. Conn HO. Hepatic encephalopathy. In: Schiff L, Schiff ER. editors. Diseases of the Liver. 7th ed. Philadelphia: Lippicott, 1993:1036-60.

14. Bajaj JS, Cordoba J, Mullen KD. Review article: the design of clinical trials in hepatic encephalopathy - an International Society for Hepatic Encephalopathy and Nitrogen Metabolism (ISHEN) consensus statement. Aliment Pharmacol Ther 2011;33:739-47.

15. Sherlock S, Summerskill WH, White LP, et al. Portalsystemic encephalopathy; neurological complications of liver disease. Lancet 1954;267:454-7.

16. Agrawal S, Umapathy S, Dhiman RK. Minimal Hepatic Encephalopathy Impairs Quality of Life. J Clin Exp Hepatol 2015;5:S42-8.

17. Vaughn-Sandler V, Sherman C, Aronsohn A, et al. Consequences of perceived stigma among patients with cirrhosis. Digestive Diseases and Sciences 2014;59:681-6.

18. Shaw J, Bajaj JS. Covert Hepatic Encephalopathy: Can My Patient Drive? J Clin Gastroenterol 2017;51:118-26.

19. Volk ML, Tocco RS, Bazick J, et al. Hospital readmissions among patients with decompensated cirrhosis. Am J Gastroenterol 2012;107:247-52.

20. Bajaj JS, Reddy KR, Tandon P, et al. The 3-month readmission rate remains unacceptably high in a large North American cohort of patients with cirrhosis. Hepatology 2016;64:200-8.

21. Montagnese S, Amato E, Schiff S, et al. A patients' and caregivers' perspective on hepatic encephalopathy. Metab Brain Dis 2012;27:567-72.

22. Montagnese S, Bajaj JS. Impact of Hepatic Encephalopathy in Cirrhosis on Quality-of-Life Issues. Drugs 2019;79:11-6.

23. Leise MD, Poterucha JJ, Kamath PS. Management of Hepatic Encephalopathy in the Hospital. Mayo Clin Proc 2014;89:241-53.

24. Patidar KR, Thacker LR, Wade JB, et al. Symptom domain groups of the patient-reported outcomes measurement information system tools independently 
predict hospitalizations and re-hospitalizations in cirrhosis. Dig Dis Sci 2017;62:1173-9.

25. Stepanova M, Mishra A, Venkatesan C. In-hospital mortality and economic burden associated with hepatic encephalopathy in the United States from 2005 to 2009. Clin Gastroenterol Hepatol 2012;10:1034-41.e1.

26. Bannister CA, Orr JG, Reynolds AV, et al. Natural history of patients taking rifaximin- $\alpha$ for recurrent hepatic encephalopathy and risk of future overt episodes and mortality: a post-hoc analysis of clinical trials data. Clin Ther 2016;38:1081-9.e4.

27. Kim WR, Kamath PS, Shah N. Utilization and outcome of critical care in patients with cirrhosis in the US. Hepatology 2010;52:910A-911A.

28. Tapper EB, Halbert B, Mellinger J. Rates of and Reasons for Hospital Readmissions in Patients With Cirrhosis: A Multistate Population-based Cohort Study. Clin Gastroenterol Hepatol 2016;14:1181-8.e2.

29. Neff Guy W, Frederick RT. Assessing treatment patterns in patients with overt hepatic encephalopathy. Hepatology 2012;56:945A.

30. Chirapongsathorn S, Krittanawong C, Enders FT, et al. Incidence and cost analysis of hospital admission and 30day readmission among patients with cirrhosis. Hepatol Commun 2018;2:188-98.

31. Masadeh MM, Hussain F, Spratt H, et al. A novel model to predict the likelihood of readmission within 30 days in patients hospitalized with liver cirrhosis. Gastroenterology 2014;146:S986.

32. Di Pascoli M, Ceranto E, De Nardi P, et al.

Hospitalizations Due to Cirrhosis: Clinical Aspects in a Large Cohort of Italian Patients and Cost Analysis Report. Dig Dis 2017;35:433-8.

33. Ladegaard Grønkjær, L, Hoppe Sehstedt T, et al. Overt Hepatic Encephalopathy Experienced by Individuals With Cirrhosis A Qualitative Interview Study. Gastroenterology Nursing 2018;41:468-76.

34. Flamm SL. Considerations for the Cost-Effective

doi: $10.21037 /$ jhmhp-20-23

Cite this article as: Flamm SL, Bajaj JS, Saab S, Brown RS Jr. The role of the hospitalist in the continuum of care for patients with hepatic encephalopathy: treatment of inpatient episodes and preventing outpatient recurrence and readmissions. J Hosp Manag Health Policy 2020;4:37.
Management of Hepatic Encephalopathy. Am J Manag Care 2018;24:S51-61.

35. Congly SE, Leise MD, Kim WR. Cost effectiveness of rifaximin in the treatment of hepatic encephalopathy. Hepatology 2013;58:869A.

36. Riggio O, Nardelli S, Gioia S, et al. Management of Hepatic Encephalopathy as an Inpatient. Clin Liver Dis (Hoboken) 2015;5:79-82.

37. Al-Busafi SA, McNabb-Baltar J, Farag A et al. Clinical manifestations of portal hypertension. Int J Hepatol 2012;2012:203794.

38. Kumral D, Qayyum R, Roseff S, et al. Adherence to Recommended Inpatient Hepatic Encephalopathy Workup. J Hosp Med 2019;14:157-60.

39. Bass NM, Mullen KD, Sanyal A, et al. Rifaximin treatment in hepatic encephalopathy. N Engl J Med 2010;362:1071-81.

40. Sharma BC, Sharma P, Lunia MK, et al. A randomized, double-blind, controlled trial comparing rifaximin plus lactulose with lactulose alone in treatment of overt hepatic encephalopathy. Am J Gastroenterol 2013;108:1458-63.

41. Sharma BC, Sharma P, Agrawal A, et al. Secondary prophylaxis of hepatic encephalopathy: an open-label randomized controlled trial of lactulose versus placebo. Gastroenterology 2009;137:885-891:891.e1.

42. Agrawal A, Sharma BC, Sharma P, et al. Secondary prophylaxis of hepatic encephalopathy in cirrhosis: an open-label, randomized controlled trial of lactulose, probiotics, and no therapy. Am J Gastroenterol 2012;107:1043-50.

43. Oey RC, Buck LEM, Erler NS, et al. The efficacy and safety of rifaximin- $\alpha$ : a 2-year observational study of overt hepatic encephalopathy. Therap Adv Gastroenterol 2019;12:1756284819858256.

44. Neff GW, Kemmer N, Zacharias VC, et al. Analysis of hospitalizations comparing rifaximin versus lactulose in the management of hepatic encephalopathy. Transplant Proc 2006;38:3552-5. 